\title{
La utilización de las notificaciones de las aplicaciones móviles en los medios de comunicación españoles
}

\author{
The use of notifications from mobile applications in the Spanish \\ media
}

Javier de Sola Pueyo. Universidad de Zaragoza. España.

jdesola@unizar.es

$[\mathrm{CV}]$ (1) $\mathrm{G}$

Miguel Ángel Ortiz Sobrino. Universidad Complutense de Madrid. España. maortiz@ccinf.ucm.es

[CV] $\mathrm{C}$

Este artículo ha sido realizado en el marco del Grupo de Investigación en Comunicación e Información Digital (S29-17R), reconocido como grupo de Referencia del Gobierno de Aragón y financiado por el Fondo Social Europeo de Desarrollo Regional (FEDER).

Cómo citar este artículo / Referencia normalizada

De Sola-Pueyo, J. y Ortiz-Sobrino, M. A. (2021). La utilización de las notificaciones de las aplicaciones móviles en los medios de comunicación españoles. Revista Latina de Comunicación Social, 79, 283-302. https://www.doi.org/10.4185/RLCS-2021-1516

\section{RESUMEN}

Introducción: Los teléfonos móviles se han convertido en un canal de comunicación más para los medios de comunicación en los últimos años. Esta investigación analiza cómo la radio, la prensa y la televisión española emplean las notificaciones para enviar contenido periodístico a los usuarios de sus aplicaciones móviles. Metodología: se ha realizado un análisis de contenido cuantitativo de 1.226 notificaciones recibidas en las aplicaciones móviles de los nueve principales medios españoles que disponen de app móvil: SER, COPE, Onda Cero, Radio Nacional de España, El País, El Mundo, $A B C$, La Vanguardia y RTVE. Resultados: el estudio revela que los medios españoles remiten notificaciones, fundamentalmente, con un propósito informativo y de narración de eventos en directo, y que lo hacen, especialmente, para abordar asuntos relacionados con el deporte, la política nacional y, en la actualidad, la crisis sanitaria, económica y social provocada por la COVID-19. La investigación muestra diferencias notables entre las estrategias de los distintos medios de comunicación estudiados y pone de manifiesto una escasa utilización de los elementos gráficos en las notificaciones móviles, así como de la publicidad. Conclusiones y discusión: las alertas informativas están sistematizadas en los medios de comunicación, si bien todavía presentan problemas de funcionamiento en algunos casos y una cierta homogeneidad en formatos y contenidos. Existe un notable margen de aprovechamiento, por ejemplo, en el caso de la publicidad como elemento de monetización de las propias apps. 
PALABRAS CLAVE: periodismo; periodismo móvil; medios de comunicación; aplicaciones móviles; análisis de contenido.

\begin{abstract}
Introduction: Mobile phones have become one more communication channel for the media in recent years. This research analyzes how Spanish radio, press and television use notifications to send journalistic content to users of their mobile applications. Methodology: a quantitative content analysis of 1,226 notifications received in the mobile applications of the nine main Spanish media that have a mobile app has been carried out: SER, COPE, Onda Cero, Radio Nacional de España, El País, El Mundo, ABC, La Vanguardia and RTVE. Results: the study reveals that the Spanish media send notifications, fundamentally, with an informative purpose and narration of live events, and that they do so, especially, to address matters related to sports, national politics and, currently, the health, economic and social crisis caused by COVID-19. The research shows notable differences between the strategies of the different media studied and reveals a low use of graphic elements in mobile notifications, as well as in advertising. Conclusions and discussion: informative alerts are systematized in the media, although they still present operational problems in some cases and a certain homogeneity in formats and contents. There is a notable margin of use, for example, in the case of advertising as an element of monetization of the apps themselves.
\end{abstract}

KEYWORDS: journalism; mass media; mobile journalism; mobile applications; content analysis.

\title{
CONTENIDO
}

1. Introducción. 2. Estado de la cuestión. 3. Objetivos. 4. Metodología. 5. Resultados. 6. Discusión y conclusiones. 7. Bibliografía 8. Currículum Vitae.

\section{Introducción}

En todo el planeta existen en estos momentos 5,22 billones de usuarios únicos de teléfonos móviles, una cifra que va en aumento año tras año, hasta el punto de que en la actualidad ya hay más dispositivos móviles conectados a la red que habitantes tiene la Tierra. Son datos del informe Digital 2021: Global Overview Report, que añade: los usuarios de Internet, de media, pasan prácticamente siete horas conectados a la Red, alrededor de cuatro horas utilizando el teléfono móvil y algo más de dos horas leyendo los contenidos que publican los medios de comunicación, tanto en la propia Red como de manera impresa (Kemp, 2021). Si tenemos en cuenta que el consumo de prensa en papel está cayendo, así como el consumo de medios radiofónicos (AIMC, 2020), resulta evidente concluir que cada vez es más importante para los medios alcanzar una posición destacada en la difusión de contenidos periodísticos en Internet.

Cabe resaltar, en este sentido, que las aplicaciones de teléfono móvil concentran el $92 \%$ del tiempo que los usuarios pasan empleando sus terminales. En 2020 se descargaron más de 218 billones de aplicaciones para teléfono móvil, un 7\% más que el año anterior y las de aplicaciones vinculadas con los medios de comunicación se establecieron en el sexto lugar de las más descargadas (APP Annie, 2021).

Como recoge Olivero (2017), la primera aplicación -en adelante app- para terminales móviles llegó al mercado hace alrededor de 15 años. Y ya hace cuatro años, añade esta autora, dedicábamos a la utilización de las apps el $80 \%$ del tiempo de uso de nuestros móviles, siendo España uno de los países que está a la cabeza en cuanto a la hegemonía de las aplicaciones frente a, por ejemplo, los navegadores de Internet. 
La tendencia que reflejan informes como el de Ditrendia es que, además, cada vez no solo consumamos más aplicaciones para móvil, sino que gastemos -o invirtamos- más en apps: "Se espera que los usuarios gasten un 30\% más en aplicaciones de nivel mundial [...], superando los 110 miles de millones de dólares a nivel global" (Rivero, 2018, p. 51). Asimismo, según Newman et al., "el teléfono inteligente sigue creciendo en importancia para las noticias, con dos tercios (66\%) que ahora usan el dispositivo para acceder a las noticias cada semana" (2019, p. 10). Y ejemplifican estos autores el caso de Reino Unido:

Aproximadamente cuatro de cada diez (43\%) [ciudadanos] en el Reino Unido afirman que acuden a un sitio web de noticias o aplicación primero cuando se usa un teléfono inteligente, una cifra relativamente alta casi con certeza impulsada por la popularidad de las noticias de la aplicación de la BBC. [...] El primer contacto general a través de las redes sociales ha caído seis puntos, mientras que el uso de agregadores $(11 \%)$ y alertas/notificaciones ha crecido $(10 \%)(2019$, p. 15).

\section{Estado de la cuestión}

\subsection{Dispositivos móviles, aplicaciones y medios de comunicación}

El smartphone, defiende Márquez, "puede considerarse como un nuevo tipo de metamedio, esto es, una plataforma que alberga muchos medios existentes y nuevos, que incluye la mayoría de las tecnologías y técnicas de los medios existentes, así como la invención de otras nuevas" (2017, p. 61). Es, de hecho y según este autor, el verdadero metamedio (Manovich, 2013) del siglo XXI, si asumimos que el ordenador fue el metamedio del siglo XX (2017). Como recogen Gil y Gómez de Travesedo (2018), autores como Kerckhove (2005) se refieren al teléfono móvil como la tercera pantalla, otros, es el caso de Miller (2014), como la cuarta, y hay quienes van más allá y la definen como la primera pantalla, entre otros Gardner y Davis (2014).

El desarrollo de la tecnología, en general, y de los teléfonos móviles, en particular, ha tenido un impacto en todos los ámbitos de la vida, entre ellos el periodismo, hasta el punto de provocar el nacimiento del concepto de "periodismo móvil". Parra lo define como:

El tratamiento de la información periodística que permite el envío y la recepción online de textos, imágenes estáticas [...], dinámicas y sonidos de manera integrada, así como la participación de los ciudadanos, convertidos en generadores y evaluadores de contenidos, todo ello utilizando las posibilidades tecnológicas de la tercera generación de la telefonía móvil (2008, p. 1).

El surgimiento de estos nuevos canales a través de los que realizar y comunicar informaciones periodísticas no implica, necesariamente, la desaparición de otros anteriores, sino que, en línea con Cobos, unos y otros pueden ser complementarios: "Las plataformas móviles representan un nuevo cambio tecnológico en la industria de la prensa con lo que ganan espacio como un soporte más para la distribución de información noticia, con lo que reorganizan el ecosistema existente en este sentido" (2012, p. 87). El binomio que conforman dispositivos móviles-medios de comunicación ha despertado el interés de la academia, en especial, a partir del año 2013 y, entre 2008 y 2018 se traduce en la publicación de 199 artículos en la base de datos Web of Science (López-García et al., 2019).

Ente las ventajas que brindan los teléfonos móviles como canales de comunicación, Martínez (2014) destaca la conexión entre medios y usuarios, mientras que Aguado y Navarro (2013) resaltan la multiplicidad de posibilidades para el contenido y para el usuario. Por su parte, García (2013) 
subraya las ventajas que implican también para los propios profesionales de los medios a la hora de elaborar sus contenidos periodísticos.

Cobos resume la evolución de los contenidos de los medios escritos en los móviles en cuatro grandes fases: la de las alertas a través de los mensajes de texto (SMS), el paso de los portales WAP a los portales móviles, la aparición de las aplicaciones o apps y la edición para dispositivos digitales de lectura o e-readers (2012, pp. 88-89). La llegada de las aplicaciones móviles implica, como recuerda Robledo-Dioses, que el contenido sea gestionado "como un servicio, una experiencia que se ajuste a las cambiantes necesidades de los usuarios" (2017, p. 17).

Las aplicaciones móviles son "un tipo de software específico que se instala en dispositivos móviles de última generación como smartphones y tabletas, y permite ejecutar diferentes tareas enfocadas directamente a la interacción directa con el usuario" (Pulgar y Maniega, 2012, p. 130). En la actualidad, como exponen Ramos del Cano y González-Molina, los estudios sobre aplicaciones móviles creadas por medios de comunicación se resumen en cinco enfoques: diseño, interactividad, presencia de recursos multimedia, modelos de negocio y adaptación de contenidos al entorno móvil (2015, p. 45).

En este sentido, estudios recientes como el de Gómez-García et al. (2019) ahondan en el contexto en el que se sitúan estas apps y su influencia desde el punto de vista de quienes las desarrollan. Centrando su investigación en las apps sobre el discurso político en torno al presidente de Estados Unidos Donald Trump, detectan casi un centenar (88) de aplicaciones con más de 10.000 descargas y averiguan que los propósitos de los desarrolladores son tanto económicos como de corte ideológico.

Aunque no es uno de los propósitos de la investigación describir los rasgos característicos de diseño, presentación y adaptación de contenidos en las apps, sí consideramos pertinente resumirlas brevemente. Larrondo y Teixeira, que inciden en la escasa producción científica al respecto, sintetizan estos rasgos en seis claves:

1. Interfaz simple, clara e intuitiva.

2. Buen diseño y estética.

3. Uso de capas de profundización o niveles hipertextuales de acceso a la información.

4. Explotar las posibilidades táctiles distintivas del soporte.

5. Amplio uso de los diferentes códigos o formatos de medios, especialmente del vídeo, evitando redundancias o duplicidades, esto es, que dos tipos de contenido en distintos medios cuenten lo mismo (por ejemplo, en texto y vídeo).

6. Integración multimedia, ya que proporciona la historia de una manera más natural que la mera yuxtaposición de contenidos en distintos formatos de medios (Larrondo y Teixeira, 2016, pp. 781-782).

Asimismo, Canavilhas y Cavallari resumen los rasgos de estos contenidos periodísticos en dispositivos móviles en seis ítems: accesibilidad, instantaneidad, multimedialidad, hipertextualidad, interactividad y globalidad (2011, p. 55). Por último, y aunque también se escapa del objeto del presente estudio, destacaremos los estudios de Costa-Sánchez (2014) y Nel y Westlund (2011) en relación con la interacción y participación de los usuarios.

\subsection{Las notificaciones push}

Uno de esos rasgos, el de la instantaneidad, guarda una estrecha relación con la aparición de las notificaciones móviles, objeto de esta investigación y también denominadas como alertas móviles, notificaciones push o mensajes push (Ling et al., 2020). Entendiendo que todos los referidos son 
conceptos sinónimos, destacamos que, según autores como Wheatley y Ferrer-Conill, lo relevante de estas notificaciones es que comunican a los medios con sus audiencias en una distribución de noticias que destaca por tres aspectos:

Pasa por alto las redes sociales y los agregadores de noticias, llegando directamente a los lectores; altera la agencia y el control de la personalización temporal de las noticias; y refuerza el móvil como el lugar de contacto entre las organizaciones de noticias y las audiencias (2020, p. 1).

Esta idea entronca con la tesis de Duffy et al. (2020) de que las notificaciones móviles resultan especialmente interesantes porque permiten proporcionar información con mayor flexibilidad en el lugar y el momento en que acceden a las noticias.

Pero, volviendo al ya citado estudio de Wheatley y Ferrer-Conill (2020) sobre la temporalidad de las notificaciones automáticas en varios países europeos, estos autores concluyen que los medios emplean el teléfono móvil no solo para atraer nuevos usuarios, sino también para mantener la atención de los ya existentes. Es este uno de los escasos estudios de relevancia sobre notificaciones push que se han realizado. Previamente, Fidalgo (2009) abordó la cuestión en el caso de los medios de comunicación portugueses, si bien extrajo una conclusión de utilidad para todos con independencia de su procedencia geográfica: una de las claves del éxito de estas notificaciones reside en que los medios conozcan cuántas alertas, de qué tipo y con qué frecuencia desean recibir las personas.

Otro interesante trabajo es el de Brown (2018), quien, en dos estudios comparativos en 2017 y 2018 aborda el modelo estadounidense. Y concluye que de un año a otro se observa que los medios envían más alertas, con más información y, en definitiva, que evolucionan hacia un mejor trabajo.

\subsection{Caracterización del servicio de notificaciones en las apps de los medios estudiados}

La investigación se centra en las notificaciones de las apps móviles de Cadena SER, COPE, Onda Cero, Radio Nacional de España, El País, El Mundo, ABC, La Vanguardia y Radio Televisión Española. Como es lógico, todas las apps tienen diferentes funcionalidades como la emisión en directo en el caso de las radios y televisiones, la publicación de contenido periodístico escrito en todo caso, información sobre programas, autores o secciones, etc. Algunas de esas diferencias están estrechamente relacionadas con la diferente naturaleza de la prensa, la radio y la televisión. No obstante, en este punto, nos centraremos en lo que concierne a la investigación: las notificaciones.

Como idea general, cabe destacar que se trata de modelos de app, y, por tanto, de notificaciones, distintos entre sí y con las particularidades que se exponen a continuación. La nota común es que todas ofrecen la posibilidad de personalizar esas notificaciones a través del menú de configuración de la propia app con una única excepción, el diario $A B C$, que requiere la habilitación de las notificaciones a través de los ajustes de configuración del propio teléfono móvil.

Las apps de RTVE, ABC, El Mundo, RNE, COPE y Onda Cero no brindan ninguna opción de personalización de las notificaciones más allá de activarlas o desactivarlas.

La app de Cadena SER permite activar o desactivar las notificaciones diferenciándolas en tres grandes categorías: Última hora, Te lo cuenta la SER y Deportes. De un modo similar, La Vanguardia también permite personalizar la activación de sus notificaciones por autores y por las categorías Última hora, Deportes, La Contra y Selección Vanguardia. 
En el caso de El País, la aplicación permite al usuario silenciar las notificaciones en el horario que determine y activar o desactivar tres tipos de notificaciones específicamente: alertas de última hora, claves del día y avisos y deportes. Asimismo, se ofrece al usuario seguir temas o autores.

Así pues, como se verá en el apartado de metodología, la activación de todas las notificaciones sin distinción evita que pueda haber diferencias que afecten a los resultados. Del mismo modo, la imposibilidad en las nueve apps de activar o desactivar la publicidad vinculada a las notificaciones también impide cualquier sesgo en los resultados.

\section{Objetivos}

El objetivo general de la investigación es conocer cómo utilizan los principales medios de comunicación de prensa escrita, radiofónicos y televisivos las notificaciones vinculadas con cada una de sus aplicaciones para teléfonos móviles, un campo tan poco estudiado en su aplicación práctica desde la academia (Westlund, 2015) como necesario estudiar (Varona et al., 2017). Este objetivo principal anteriormente enunciado se concreta en otros más específicos, que son los siguientes:

O1. Determinar qué uso realizan los medios de comunicación españoles desde un punto de vista cuantitativo: observar cuántas notificaciones envían y en qué momentos del día lo hacen.

O2. Comprobar si, desde un punto de vista técnico, las notificaciones -y por añadidura las aplicaciones móviles- funcionan correctamente, de manera individual, y con qué velocidad de respuesta ante temas de actualidad, en comparación con las aplicaciones de otros medios.

O3. Conocer cuáles son las temáticas en las que se centran las notificaciones y a través de qué géneros periodísticos se construyen las informaciones que se envían a los usuarios.

O4. Establecer si los medios aprovechan estas herramientas para insertar publicidad.

\section{Metodología}

Para alcanzar dichos objetivos se ha llevado a cabo un análisis de contenido cuantitativo de todas las notificaciones recibidas. Como señalan diferentes autores (Berelson, 1952; Wimmer y Dominick, 1996), esta técnica permite describir de forma objetiva y sistemática el fenómeno estudiado. Además, la decisión de que el análisis de contenido fuese cuantitativo -y no cualitativo- se debe a que, como recoge de Sola, un criterio indispensable de toda investigación es que esta ha de ser "realizable" (2020, p. 211). Y, siguiendo a Krippendorff (2004), esta técnica permite trabajar con grandes volúmenes de información.

Durante la investigación, se empleó un terminal móvil Xiaomi Redmi 7. La elección se debe a que cuenta con sistema operativo Android que, en la actualidad, es el que tiene una mayor presencia en el mercado. De hecho, según la consultora IDC, especializada en tecnología, los dispositivos Android representaron en 2019 más del 86\% frente al 14\% de los sistemas operativos iOS, vinculados con Apple (Mena, 2020).

Seleccionado el terminal móvil con el que se realizaría la investigación, se procedió a la descarga de las aplicaciones móviles de Cadena SER, COPE, Onda Cero, Radio Nacional de España, El País, El Mundo, ABC, La Vanguardia y Radio Televisión Española. La decisión de estudiar estos medios se justifica en que los cuatro primeros son las cuatro emisoras de radio más escuchadas en España (EGM, 2021); y los cuatro siguientes, los cuatro diarios más leídos en España (EGM, 2021). Con respecto a las cadenas de televisión, en una primera aproximación a la investigación ya se detectó la imposibilidad de analizarlas con un procedimiento similar al de diarios y cadenas radiofónicas por un motivo principal: la inexistencia de aplicaciones informativas de los medios televisivos. Por ello, se decidió estudiar la única que compartía esta misma línea de ser una app informativa, que resultó ser 
RTVE. El resto de las principales cadenas -Antena 3, Cuatro, Telecinco y La Sexta- no disponen de una app de contenido informativo, sino que, funcionan, más bien, como plataformas de contenido a la carta y en directo.

Una vez descargadas las aplicaciones se habilitó en todas ellas la recepción de alertas y/o notificaciones y se autorizaron todos y cada uno de los permisos que se requerían para recibir contenido.

Este procedimiento de descarga de las aplicaciones y autorización de permisos se realizó también en un terminal Huawei P40 Lite para comprobar que, en efecto, las notificaciones llegaban de manera adecuada y que el terminal de referencia para la investigación las recibía correctamente. Y se pudo constatar que, en efecto, la recepción de notificaciones era idéntica en ambos terminales, por lo que proseguimos con la investigación con el móvil inicialmente comentado. Esta fase sirvió también para la realización de un siempre necesario pretest (Victoria, 2002) que nos permitió comprobar que el código de análisis elaborado, que se expone a continuación, permitía dar respuesta a los objetivos que se planteaba alcanzar la investigación.

Se estudiaron todas las notificaciones recibidas entre el 1 y el 14 de enero de 2021 y el 2 y el 15 de abril de 2021, con independencia de la hora de recepción, de si funcionaban o no correctamente o de cualquier otro parámetro por entender que cualquier aspecto, incluso el mal funcionamiento de las notificaciones, nos aportaría información relevante para el estudio. La selección de las fechas se determinó de acuerdo a un muestreo aleatorio, pero con la premisa de que fueran dos períodos de dos semanas para que, en caso de que se produjera algún hecho noticioso que exigiese una cobertura periodística durante varios días, el estudio lo detectase. Asimismo, constatamos que los dos períodos se circunscribían en momentos de un notable interés informativo -la evolución de la pandemia en el mundo, asalto al Capitolio de Estados Unidos, competiciones deportivas, impacto en España de una borrasca con consecuencias históricas, etc.--

El código de análisis empleado en el estudio está compuesto por once categorías que se centran tanto en aspectos formales como aspectos de contenido elaboradas de acuerdo a criterios de homogeneidad, pertinencia, claridad y productividad (Sánchez Aranda, 2005, pp. 219-220). Las categorías formales aluden a aspectos como la fecha y hora de recepción de la notificación, el medio de comunicación que la emite, su correcto funcionamiento o el destino al que dirige la notificación al hacer click sobre ella. Por otra parte, las categorías de contenido nos permiten analizar la temática general de las notificaciones recibidas, los géneros periodísticos y/o mecanismos comunicativos a través de los que se articulan, la inclusión o no de imágenes y/o publicidad, etc. Todas las categorías están incluidas en el código de análisis que se presenta a continuación. 
RLCS, Revista Latina de Comunicación Social, 79, 283-302

[Investigación] DOI: 10.4185/RLCS-2021-1516| ISSN 1138-5820| Año 2021

Tabla 1. Código de análisis

\begin{tabular}{|c|c|}
\hline Fecha de recepción de la notificación & $\begin{array}{l}\text { La correspondiente en los períodos analizados (1-14 } \\
\text { de enero de } 2021 \text { y } 2 \text { a } 15 \text { de abril de } 2021) \text {. }\end{array}$ \\
\hline Medio de comunicación emisor & $\begin{array}{l}\text { 1. SER } \\
\text { 2. COPE } \\
\text { 3. Onda Cero } \\
\text { 4. Radio Nacional de España (RNE) } \\
\text { 5. El País } \\
\text { 6. El Mundo } \\
\text { 7. ABC } \\
\text { 8. La Vanguardia } \\
\text { 9. Radio Televisión Española (RTVE) }\end{array}$ \\
\hline Hora de recepción de la notificación & $\begin{array}{l}\text { 1. Entre las } 00: 00 \mathrm{~h} \text { y las } 05: 59 \mathrm{~h} \\
\text { 2. Entre las } 06: 00 \mathrm{~h} \text { y las } 11: 59 \mathrm{~h} \\
\text { 3. Entre las } 12: 00 \mathrm{~h} \text { y las } 17: 59 \mathrm{~h} \\
\text { 4. Entre las } 18: 00 \mathrm{~h} \text { y las } 23: 59 \mathrm{~h}\end{array}$ \\
\hline Temática general de la notificación & $\begin{array}{l}\text { 1. Política o Nacional } \\
\text { 2. Internacional } \\
\text { 3. Deporte } \\
\text { 4. Sucesos y Tribunales } \\
\text { 5. Tiempo } \\
\text { 6. Economía y Empleo } \\
\text { 7. Sociedad } \\
\text { 8. Cultura } \\
\text { 9. Coronavirus } \\
\text { 10. Violencia machista } \\
\text { 11. Loterías y juegos } \\
\text { 12. Otros } \\
\text { 13. Varios de los anteriores }\end{array}$ \\
\hline $\begin{array}{l}\text { ¿Funciona correctamente la notificación al hacer click } \\
\text { para visualizarla? }\end{array}$ & $\begin{array}{l}\text { 1. Sí } \\
\text { 2. No }\end{array}$ \\
\hline ¿Dónde dirige el vínculo de la notificación? & $\begin{array}{l}\text { 1. A la app móvil } \\
\text { 2. A la web del medio de comunicación } \\
\text { 3. A la app móvil, pero indicando que el contenido } \\
\text { ha de verse en la web. }\end{array}$ \\
\hline $\begin{array}{l}\text { ¿Incorpora la notificación alguna imagen en la } \\
\text { previsualización? }\end{array}$ & $\begin{array}{l}\text { 1. Sí } \\
\text { 2. No }\end{array}$ \\
\hline $\begin{array}{l}\text { ¿La notificación es un tema propio del medio de } \\
\text { comunicación que la envía? }\end{array}$ & $\begin{array}{l}\text { 1. Sí } \\
\text { 2. No }\end{array}$ \\
\hline $\begin{array}{l}\text { En caso de que la respuesta a la pregunta anterior sea } \\
\text { "no", ¿en qué orden con respecto a otros medios se } \\
\text { recibe la notificación? }\end{array}$ & $\begin{array}{l}\text { 1. Primero } \\
\text { 2. Segundo } \\
\text { 3. Tercero } \\
\text { 4. Cuarto } \\
\text { 5. Quinto o posteriores }\end{array}$ \\
\hline $\begin{array}{l}\text { ¿Con qué género periodísticos se identifica la } \\
\text { publicación de la notificación? }\end{array}$ & $\begin{array}{l}\text { 1. Noticia y Crónica } \\
\text { 2. Reportaje } \\
\text { 3. Entrevista } \\
\text { 4. Opinión } \\
\text { 5. Podcast } \\
\text { 6. Directo } \\
\text { 7. Otros } \\
\text { 8. Varios de los anteriores }\end{array}$ \\
\hline $\begin{array}{l}\text { ¿Se abre una ventana de publicidad al hacer click sobre } \\
\text { la notificación antes de llevarnos al contenido } \\
\text { periodístico? }\end{array}$ & $\begin{array}{l}\text { 1. Sí } \\
\text { 2. No }\end{array}$ \\
\hline
\end{tabular}

Fuente: Elaboración propia 


\section{Resultados}

Del estudio de los datos obtenidos en la investigación se aprecia que no todos los medios de comunicación están realizando un aprovechamiento igual, ni semejante, de la herramienta de las notificaciones. De hecho, en el Gráfico 1 se aprecia que son las dos emisoras de radio generalistas líderes en España las que realizan un mayor uso de las notificaciones: Cadena SER y COPE concentran, con 273 y 230 , el $22,29 \%$ y el $18,78 \%$ del total de alertas recibidas, respectivamente. Y resulta llamativo que las cifras de ambas, sumadas a las de otra cadena radiofónica, Onda Cero (el $9,63 \%$, esto es, 118 notificaciones) representan más de la mitad del total de notificaciones, superando a la suma de todos los periódicos y de las dos aplicaciones de la radiotelevisión pública estudiadas.

Por lo que respecta a los periódicos, encontramos una estrategia relativamente similar: las notificaciones de El País suponen el 13,06\% del total (160 notificaciones); las de La Vanguardia, el 11,67\% (143); las de $A B C$, el 10,12\% (124); y las de El Mundo, el 5,63\% (69). Por último, es sorprendente la escasa utilización de la app de $R N E$ para enviar alertas (5 notificaciones, es decir, el $0,41 \%$ del total). Y, teniendo en cuenta este último hecho, tampoco parece elevado el porcentaje de alertas enviadas mediante la app de RTVE: el 8,41\% del total (103 notificaciones).

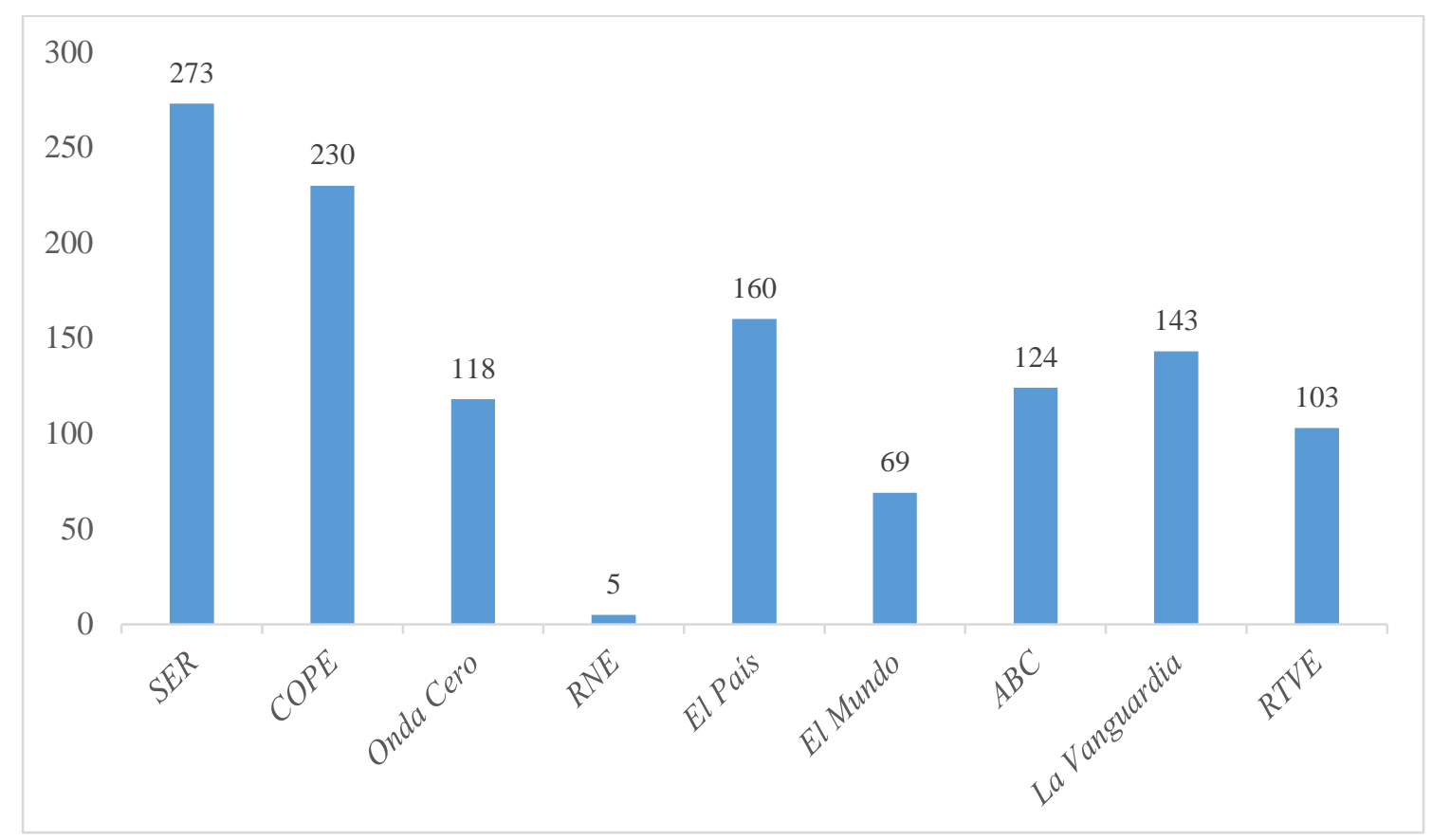

Gráfico 1: Distribución de las notificaciones móviles por medio de comunicación

Fuente: Elaboración propia

\subsection{Aspectos formales de la cobertura}

Las notificaciones emitidas por los medios no siguen, en general, un patrón definido, sino que su mayor o menor presencia está vinculada con los diferentes hechos noticiosos que se producen cada día. Esto, como se verá más adelante, está estrechamente relacionado con los tipos de publicaciones que envían los medios en sus notificaciones y los géneros periodísticos a través de los que se presentan.

Así pues, como se observa en el Gráfico 2, los días que más notificaciones se recibieron fueron el miércoles 6 de enero, el sábado 9 de enero y el miércoles 13 de enero; estas tres fechas concentran, 
respectivamente, el 5,96\%, 5,88\% y 5,39\% de las notificaciones. Y lo hacen porque en cada uno de esos días sucedió un acontecimiento noticioso especialmente relevante: el 6 de enero, la toma del Capitolio en Washington; el 9 de enero, las consecuencias más severas de la borrasca Filomena en España; el 13 de enero, la acusación de la Cámara de Representantes de Estados Unidos del segundo impeachment contra Donald Trump.

Sí se observa, con excepciones contadas, un rasgo común a los diferentes períodos analizados: los domingos y los días festivos, son los que menos notificaciones envían las aplicaciones de los medios. Esto queda de manifiesto el viernes 1 de enero -Día de Año Nuevo-, y los domingos 10 de enero y 4 de abril, jornadas en las que apenas se recibieron el $0,73 \%, 1,55 \%$ y $1,71 \%$ del total de notificaciones.

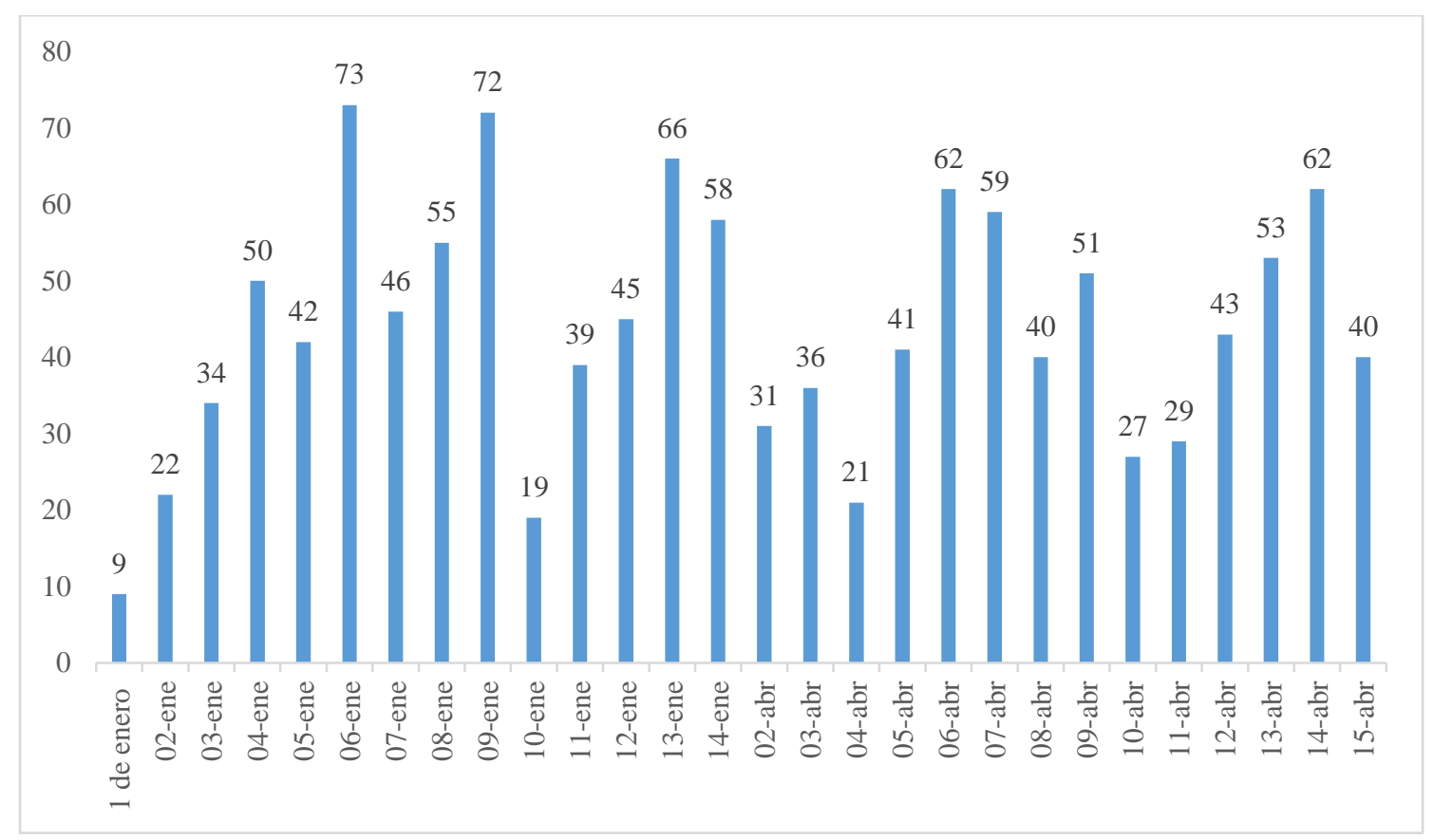

Gráfico 2: Número de notificaciones recibidas según el día de recepción

Fuente: Elaboración propia

La investigación sí permite detectar una tendencia clara en relación con el horario con el que se emiten las notificaciones. Estas se incrementan conforme avanza el día: la franja horaria que va desde las 00:00 horas a las 05:59 horas apenas representa el 0,98\% del total de notificaciones recibidas; el período entre las 06:00 horas y las 11:59 horas, el 25,06\%; el lapso siguiente, entre las 12:00 horas y las 17:59 horas, el 31,59\%; y, por último, el intervalo vespertino-nocturno, el que va desde las 18:00 horas a las 23:59 horas concentra el 42,20\% de las notificaciones.

Este fenómeno se produce por dos cuestiones que se verán más adelante: notificaciones que resumen la actualidad del día y, especialmente, notificaciones sobre eventos deportivos que se están desarrollando en tiempo real en esa franja horaria. Y se repite tanto en el conjunto de medios como en cada uno por separado. Si acaso, encontramos una pequeña excepción: El País envía más notificaciones en la franja horaria matinal que en la vespertina y de tarde-noche. Y RNE concentra casi todos sus envíos (80\%) entre las 12:00 y las 18:00 horas, si bien, como se verá, apenas emite notificaciones. 
En cuanto al correcto funcionamiento de las notificaciones, y aunque el dato, en global, es que el $83,35 \%$ de las notificaciones recibidas sí funcionaron correctamente, es necesario precisar ese porcentaje desagregándolo. Los datos de un adecuado funcionamiento están por encima del $98 \%$ en los casos de SER, COPE, RNE, El País, El Mundo y La Vanguardia, y muy próximos a este porcentaje en $R T V E(93,20 \%)$. Sin embargo, son muy bajos en dos medios: solo el $24,58 \%$ de las notificaciones de Onda Cero se abrieron correctamente al hacer click sobre ellas; y el porcentaje es todavía inferior en el caso de $A B C(21,77 \%)$. Evidentemente, de poco sirve enviar alertas con inmediatez y con contenidos interesantes, si no funcionan.

Desde un punto de vista formal es reseñable también que hay una mayoría de notificaciones $(50,34 \%)$ que dirigen no a la app, sino a un enlace web, y que un $0,68 \%$ de las notificaciones, al abrirlas, sí llevan a la app, pero allí aparece un mensaje en el que se precisa que el contenido ha de visualizarse en la web. Por el contrario, el 48,98\% de las alertas están direccionadas a la app y el contenido se puede ver sin problema en esta.

Nuevamente, encontramos diferencias importantes entre medios. Casi siempre somos dirigidos a visualizar el contenido en la propia app al hacer click en las notificaciones de RNE (100\%), El País (94,34\%), El Mundo (94,12\%), RTVE (98,97\%) y La Vanguardia (98,59\%). Entendemos esto como un aspecto positivo del funcionamiento de las aplicaciones que, sin embargo, no se repite en el resto de medios. De hecho, ocurre todo lo contrario en los casos de ABC, COPE, Cadena SER y Onda Cero que, respectivamente, envían a un enlace web en el 100\%, 93,86\%, 92,51\% y 51,61\% de las ocasiones.

\subsection{El contenido de las notificaciones de las aplicaciones móviles}

\subsubsection{Temática de las notificaciones}

En relación con el contenido de las notificaciones estudiadas cabe destacar, en primer lugar, que, pese a que existe una notable diversidad temática, hay algunos campos que predominan sobre los demás. Y, en especial, uno: la pandemia del coronavirus representa el 33,96\% de las notificaciones enviadas por los medios de comunicación analizados, en conjunto, algo esperable por otra parte.

A continuación, y como se expone en el Gráfico 3, las alertas sobre contenidos de deporte $(15,02 \%)$ y las relativas a la política española $(13,14 \%)$ son las más habituales. Y tienen también una importancia notable, de acuerdo con nuestra investigación, las notificaciones sobre el tiempo $(9,80 \%)$, acerca de información internacional $(8,90 \%)$ y las vinculadas con la economía y el empleo $(4,73 \%)$.

Interpretamos que estos datos están más relacionados con una apuesta temática mantenida en el tiempo y no tanto con los hechos noticiosos sucedidos en los períodos analizados, en concreto, ya que apenas hay diferencias en las notificaciones recibidas sobre la pandemia, deporte, política nacional y economía y empleo en los dos períodos analizados.

Hay una excepción a la afirmación anterior: el elevado porcentaje de asuntos internacionales se corresponde, básicamente, con la toma de la Casa Blanca en enero y con el juicio político contra el entonces presidente de Estados Unidos, Donald Trump. Afirmamos esto después de observar que el $80 \%$ de las notificaciones de temática internacional se recibieron entre el 6 y el 13 de enero.

También se han recibido, aunque en menor medida, notificaciones relacionadas con temas de sociedad $(2,45 \%)$, loterías y juegos $(1,47 \%)$, la religión $(1,14 \%)$, la cultura $(0,65 \%)$, la violencia 
machista $(0,41 \%)$, sobre otros temas $(3,10 \%)$ y sobre varios asuntos de diferente índole en una misma alerta $(3,67 \%)$. Esta última agrupación temática la hemos identificado con unas alertas muy específicas, las que se envían a primera hora de la mañana bajo la idea de "las noticias que hay que conocer para empezar el día", práctica habitual en El País, ABC y COPE, especialmente.

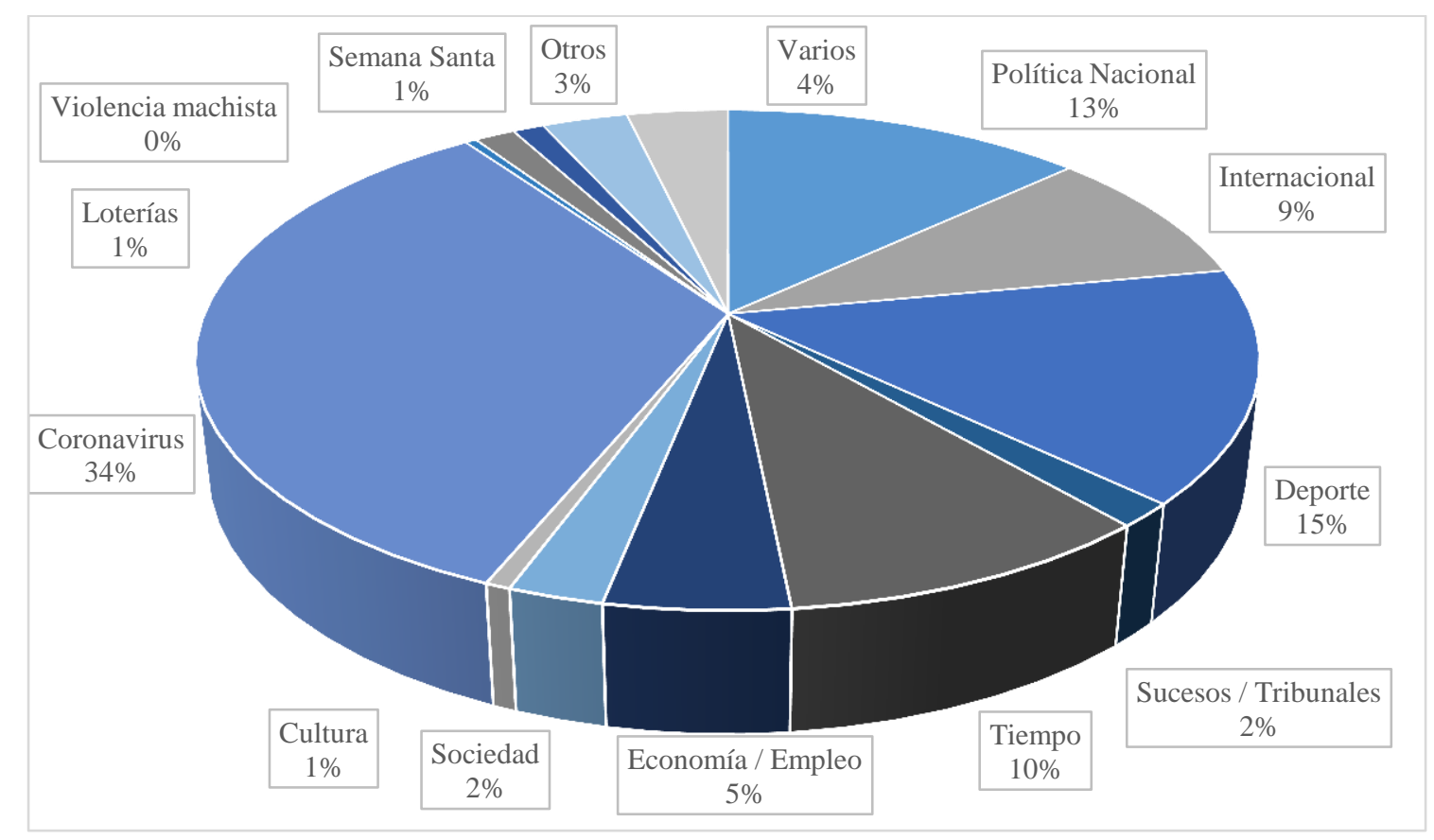

Gráfico 3: Temática de las notificaciones móviles enviadas por los medios (en porcentaje)

Fuente: Elaboración propia

Atendiendo a cada cabecera, observamos que la hegemonía de la temática vinculada con la pandemia vuelve a ser la dominante también por separado. A partir de ahí, si existen diferencias. El deporte es la segunda temática más habituales en las notificaciones de SER $(18,32 \%)$, Onda Cero $(18,80 \%)$ y La Vanguardia (26,57\%), mientras que la política nacional lo es en las coberturas de COPE $(19,13 \%)$ y $A B C(17,74 \%)$. Por otra parte, el segundo más repetido en las notificaciones de El Mundo y RTVE es el tiempo $(15,94 \%$ y $14,56 \%$ de sus alertas, respectivamente), en las de El País, los asuntos internacionales $(13,13 \%)$ y en las de $R N E$, los temas culturales $(20 \%)$.

El 37,86\% de las notificaciones son temas propios elaborados por los medios de comunicación, contenidos originales que no se repiten en otros periódicos, radios o televisiones, mientras que el $62,14 \%$ de las notificaciones son publicaciones periodísticas que se derivan de ruedas de prensa, comunicados, comparecencias oficiales, etc., y que sí se repiten en varios medios de comunicación.

Cabe destacar que prácticamente todos los medios se mueven, en este apartado, en unos datos similares de originalidad en cuanto a contenidos: El País, 43,22\%; COPE, 45,41\%; Onda Cero, 47,46\%; El País, 35\%; El Mundo, 40,58; ABC, 30,89\%. Observamos, únicamente, una excepción en positivo, Radio Nacional de España, con un $80 \%$ de notificaciones con contenido original, si bien hay que recordar que sus notificaciones son escasas. Y, en el lado opuesto, cabe reseñar que $L a$ Vanguardia y RTVE son los medios que menos alertas de contenido exclusivo envían, el 26,57\% y el $20,39 \%$, en cada caso.

\subsubsection{Empleo de los géneros periodísticos y los elementos gráficos}


Los dos elementos anteriores -la temática y la originalidad o no de las publicaciones periodísticasestán estrechamente relacionados con los géneros periodísticos empleados. De acuerdo con el Gráfico 4, las notificaciones responden, fundamentalmente, a dos criterios: información de última hora e información en vivo. Esto se deduce de que el 48,92\% de las alertas recibidas se identifiquen con noticias o crónicas y que el $29,16 \%$ lo hagan con eventos que están teniendo lugar en ese momento y que se pueden seguir al minuto en la app móvil del medo de comunicación en cuestión.

La primacía de lo noticioso y el tiempo real relega a casi el ostracismo al resto de géneros periodísticos: solo el 4\% de las notificaciones aluden a entrevistas, el 6\% a reportajes y ese mismo porcentaje a contenidos de opinión; otros géneros representan el 1\% de las notificaciones y la mezcla de varios géneros, el $5 \%$.

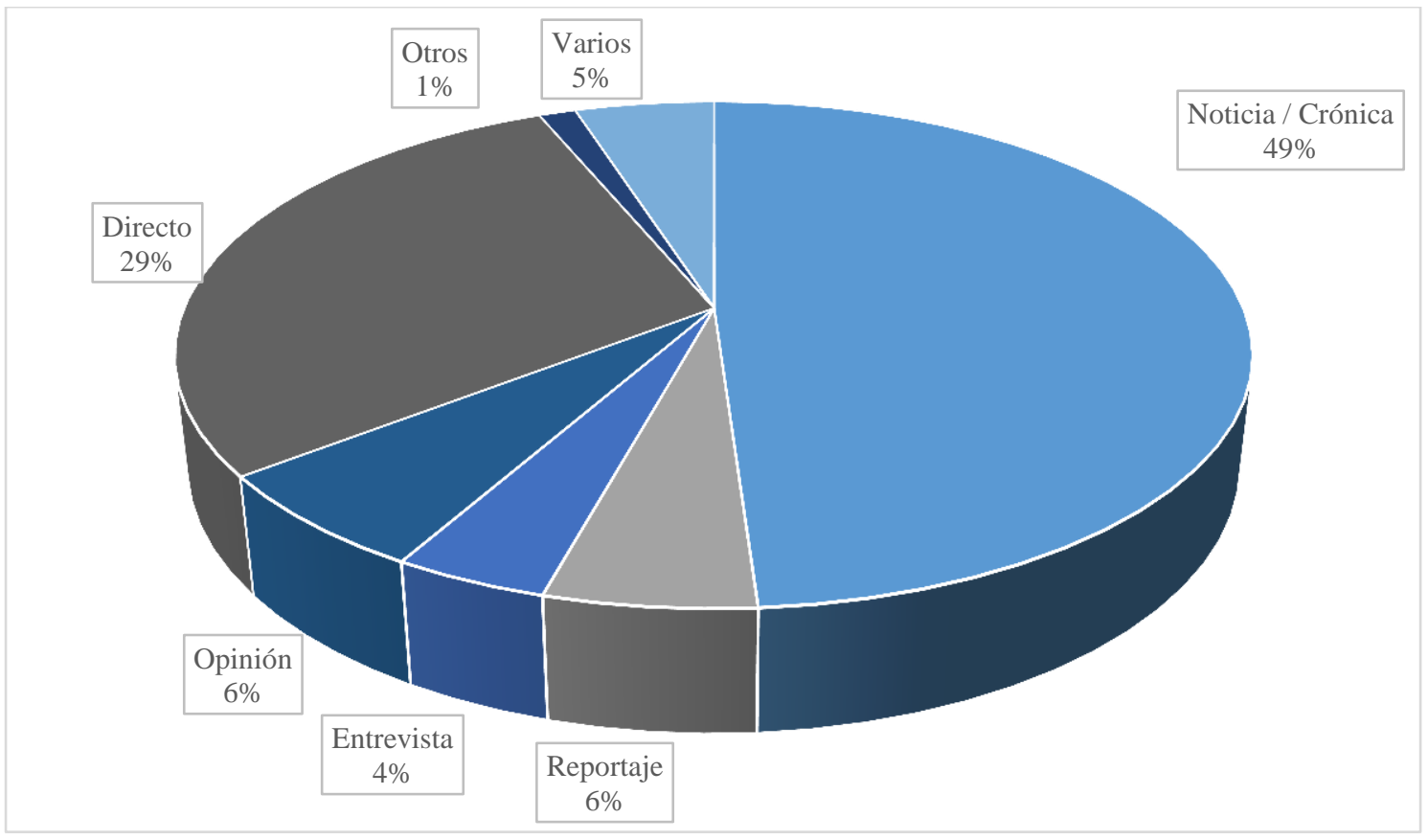

\section{Gráfico 4: Géneros periodísticos de las publicaciones enviadas como notificación (en porcentaje)}

Fuente: Elaboración propia

Si miramos a cada medio por separado, llama la atención que la Cadena SER es la que más centra sus notificaciones en noticias o crónicas (66,05\%), seguida de $A B C(54,17 \%)$ y La Vanguardia $(51,05 \%)$. Por otra parte, observamos una primacía de las notificaciones sobre directos en $R T V E$ (49,47\% de sus casos), El Mundo (41,18\%), El País (40,88\%), y Onda Cero (36,36\%). Además, es relevante de contenidos vinculados con la opinión que se recogen en los casos de Onda Cero (25\%) y COPE $(17,83 \%)$.

En cuanto a la utilización de imágenes en la previsualización de las notificaciones, llama la atención que apenas un tercio de las notificaciones -el 34,12\% exactamente- van acompañadas de un recurso gráfico, desde fotografías hasta infografías, etc. En este aspecto observamos dos tendencias claramente diferencias: hay medios que sistemáticamente emplean imágenes en sus notificaciones, y hay otros que apuestan solamente por el texto. En el primer grupo encontramos a $A B C$, Onda Cero, $R T V E$ y $R N E$, que sí incluyen imágenes en el $99,19 \%$, el $98,31 \%$, el $66,99 \%$ y el $60 \%$ de sus notificaciones, respectivamente. También lo hacen, ocasionalmente, El Mundo (37,68\% de las ocasiones) y COPE (27,39). Sin embargo, Cadena SER (3,66\%), El País (1,88\%) y La Vanguardia $(3,50 \%)$ rara vez incorporan imágenes en sus alertas. 


\subsection{Reacción y rapidez en el envío de las notificaciones según medio}

Resulta interesante detenerse en cómo reaccionan los medios analizados cuando envían notificaciones acerca de un hecho noticioso que no es una exclusiva de dichos medios. El Gráfico 5 recoge esta variable y refleja que es el diario El País el medio que más primeras notificaciones concentra (22,1\%), seguido de cerca de Cadena SER (19,89\%), COPE (16,02\%) y ABC (15,47\%). La rapidez en el envío de alertas de estos medios de comunicación queda ratificada porque también son ellos los que concentran los datos más elevados al fijarnos en quiénes envían las notificaciones en segundo lugar: SER (18,6\%), COPE (17,83\%) y El País (14,73\%). La única variación que encontramos es que el ascenso de La Vanguardia -aglutina el 17,83\% de las segundas notificacionesen detrimento de $A B C$-cae al 6,98\%-.

En el extremo más negativo, Radio Nacional de España, que no fue capaz de situar ni una sola notificación entre las cinco más rápidas entre todas las analizadas. Observamos también, como se recoge en el Gráfico 5, una capacidad de reacción lenta por parte de Onda Cero, protagonista, sobre todo, en las cuartas y quintas notificaciones más rápidas, y muy variable en $R T V E$.

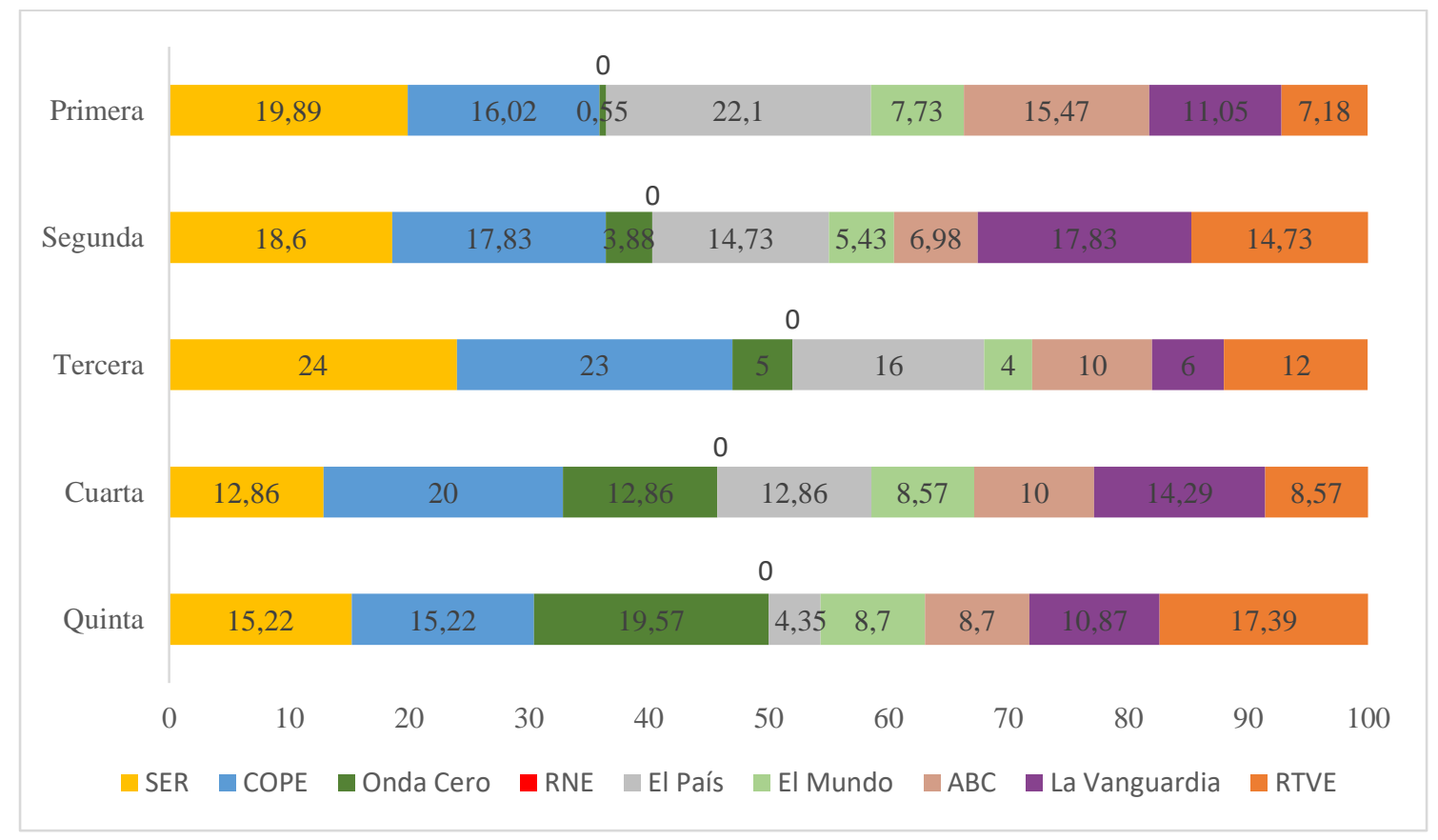

Gráfico 5: Respuesta de los medios ante temas que no son de elaboración propia (en porcentaje) Fuente: Elaboración propia

Por último, los datos revelan una infrautilización de las notificaciones como recurso publicitario: apenas el 13,93\% de las notificaciones incorporan un anuncio antes de acceder al contenido periodístico. Y solo hay cuatro medios que emplean este recurso, la Cadena SER, en el 0,38\% de sus notificaciones; RTVE, en el 1,01\% de sus notificaciones -y para autopromocionarse-; El País, en el 9,62\% de sus casos; y COPE, ya sí de una manera más sistemática, en más de la mitad de sus notificaciones $(55,86 \%)$. 


\section{Discusión y conclusiones}

La investigación permite concluir que todos los medios de comunicación españoles envían notificaciones a los usuarios de sus respectivas aplicaciones móviles, si bien lo hacen de un modo desigual. En líneas generales, las alertas informativas son algo sistematizado en los medios estudiados, lo que denota que los medios han entendido la importancia de la utilización de los recursos que ofrece la telefonía móvil. Ello es una muestra de innovación en la distribución de información periodística que, indirectamente, obliga a reinventar las competencias profesionales de los periodistas (García-Avilés et al., 2018).

Los medios líderes son los que, en general, realizan un mayor y mejor uso de las notificaciones móviles. Así lo revelan los datos cuantitativos y cualitativos de Cadena SER, Cadena COPE y El País, los más escuchados y leídos en su sector, respectivamente. Esto nos invita a preguntarnos si se debe a que también son los medios que disponen de mayores recursos económicos y humanos, cuestión que, en cualquier caso, excede a nuestra investigación.

Más allá de las diferencias entre unos y otros, los medios estudiados envían más notificaciones en las franjas de tarde $\mathrm{y}$, especialmente, de noche que en las de mañana y madrugada. Esto muestra una realidad ligeramente distinta a la observada por Read en el caso del Reino Unido, donde el autor identificó que era en el entorno de las cuatro y las cinco de la tarde cuando más notificaciones enviaban los medios (2017). En nuestro estudio, aún siendo esa una franja muy utilizada, son pasadas las seis de la tarde cuando más notificaciones push se detectan.

Como en el estudio de Wheatley y Ferrer-Conill, no existe un patrón claro sobre envío de alertas a lo largo de la semana, en nuestro caso con la excepción de que los domingos y festivos decaen notablemente los envíos, algo estrechamente relacionado con las propias prácticas profesionales del periodismo. Coincidimos con la interpretación de estos autores de que "no hay reglas estrictas con respecto a la cantidad de notificaciones que envían cada día" (2020, p. 10).

Una de las novedades que aporta este estudio es que detecta que los medios emplean las notificaciones para, fundamentalmente, retransmitir eventos que se están produciendo en ese momento en directo. También para informar sobre noticias de última hora, una práctica habitual en el periodismo (Rom y Reich, 2017). Esta idea ya ha sido subrayada como una potencialidad en estudios anteriores como el de Canavilhas: "Los teléfonos inteligentes pueden ser utilizados principalmente para noticias de última hora [...]. A través de push alerts, radios y televisiones pueden disfrutar de la proximidad del dispositivo a su usuario para atraer a los consumidores" (2013, p. 29).

La información sobre la pandemia del coronavirus, el deporte y la política nacional son los tres temas más habituales en las notificaciones enviadas por los medios. Los dos primeros están muy vinculados tanto con noticias de última hora como con eventos en vivo, mientras que la política nacional va, casi exclusivamente, ligada a lo noticioso. Si bien no existen estudios que nos permitan comparar la preponderancia de estos asuntos, la abundancia de alertas sobre política corrobora la idea de Varona et al. de que los móviles son "el complemento perfecto para unos usuarios muy dispuestos a informarse sobre política” (2017, p. 643).

Existen dos aspectos en los que se aprecia un margen de mejora evidente en las aplicaciones de los medios españoles: por un lado, en el empleo de imágenes y demás recursos gráficos en la previsualización del contenido; por otro, en la adaptación de los contenidos, ya que son muchas las alertas que no se pueden visualizar en la app, sino que dirigen al usuario a la web del medio. Esto pone en cuestión que la idea detectada por Valverde y Aguado (2010) hace una década de la 
existencia de una corriente de creación de contenido específico para los dispositivos móviles. En efecto, confirmamos esa tesis, pero advertimos de que todavía no es la dominante. De acuerdo con Brown (2018), el inadecuado empleo de las imágenes guarda relación con la falta de herramientas adecuadas en el proceso de redacción, el escaso valor de dichas imágenes debido a que tienen un tamaño excesivamente pequeño o el riesgo de repetir a menudo las mismas imágenes si los temas son similares.

Observamos, por otra parte, y con la única excepción de $C O P E$, que los medios apenas insertan publicidad en los contenidos periodísticos que envían a sus usuarios. Y entendemos que lo publicitario podría ser una vía de obtención de ingresos interesantes, más teniendo en cuenta lo que subraya Peinado y Mateos: "La monetización de las aplicaciones de los media se apoya en que el 95\% de las aplicaciones son gratuitas y el 5\% son de pago, de las que unas pocas están enfocadas a medios de comunicación con información dinámica" (2016, p. 337).

El estudio plantea algunas limitaciones. Una de ellas es que está centrada en la recepción de las notificaciones en terminales Android, y no en móviles con sistema operativo iOS que, aún representando un porcentaje muy inferior al de los primeros, también tienen una presencia notable en el mercado. Por ello, sería interesante comparar si existen o no diferencias.

Por último, la investigación abre la puerta a otras que, en el futuro, permitan determinar si existe una evolución en los puntos analizados en esta investigación o si se produce un estancamiento en las estrategias de los medios. Asimismo, y aunque se aleja de nuestro objeto de estudio en esta ocasión, resultaría también interesante ahondar en el estudio del contenido periodístico que se envía en estas notificaciones: no solo en los temas, en general, como planteamos nosotros, sino, por ejemplo, en los enfoques de esos temas.

\section{Bibliografía}

Aguado, J. y Navarro, H. (2013). Comunicación móvil, ecosistema digital e industrias culturales. En: Aguado, J., Feijóo, C., y Martínez, I. (coords.). La comunicación móvil: Hacia un nuevo ecosistema digital. Gedisa.

APP Annie (2021). State of mobile 2021. https://www.appannie.com/en/go/state-of-mobile2021/?utm_source=digital-2021\&utm_medium=partnership\&utm_campaign=ww-logo-2019101910-digital-2021-partnership\&utm_content=report-\&sfdcid=7016F000002MS1c

Asociación para la Investigación de Medios de Comunicación (AIMC) (2020). Marco general de los medios en España. https://www.aimc.es/a1mc-c0nt3nt/uploads/2020/01/marco2020.pdf

Asociación para la Investigación de Medios de Comunicación (AIMC) (2021). Estudio General de Medios. Cadenas de radio. https://reporting.aimc.es/index.html\#/main/radio

Asociación para la Investigación de Medios de Comunicación (AIMC) (2021). Estudio General de Medios. Ranking de diarios. https://reporting.aimc.es/index.html\#/main/diarios

Bausela, E. (2005). SPSS: Un instrumento de análisis de datos cuantitativos. Revista de Informática
Educativa
y Medios
Audiovisuales,
2
(4),
62-69.

http://laboratorios.fi.uba.ar/lie/Revista/Articulos/020204/A3mar2005.pdf 
RLCS, Revista Latina de Comunicación Social, 79, 283-302

[Investigación] DOI: 10.4185/RLCS-2021-1516| ISSN 1138-5820| Año 2021

Berelson, B. (1952). Content Analysis in Communication Content. University of Chicago-Columbia University.

Brown, P. (2018). Pushed Even Further: US Newsrooms View Mobile Alerts as a Standalone Platform. The Tow Center for Digital Journalism. https://www.cjr.org/tow_center_reports/newsrooms-view-mobile-alerts-as-standaloneplatform.php

Canavilhas, J. (2013). Modelos informativos para aparatos móviles: información hipermultimediática y personalizada. En: González, S., Canavilhas, J., Carvajal, M., Lerma, C. y Cobos, T. Hacia el periodismo móvil. Revista Mediterránea de Comunicación.

Canavilhas, J. y Cavallari, D. (2011). Jornalismo para plataformas móveis de 2008 a 2011: da autonomia à emancipação. Libero, 14, (28), 53-66. https://casperlibero.edu.br/wpcontent/uploads/2014/05/2-Jornalismo-para-plataformas-m\%C3\%B3veis-de-2008-a-2011.pdf

Castañeda, M. B., Cabrera, A., Navarro, Y. y de Vries, W. (2010). Procesamiento de datos y análisis estadísticos utilizando SPSS. Un libro práctico para investigadores y administradores educativos. EDIPUCRS.

Cobos, T. L. (2012). Periodismo móvil: la prensa mexicana y su incursión en plataformas móviles. $\begin{array}{llllll}\text { Casos El Universal y El Norte. } & \text { Virtualis, }\end{array}$ https://www.revistavirtualis.mx/index.php/virtualis/article/view/64

Costa-Sánchez, C. (2014). Las singularidades del medio móvil: Integración multimedia, personalización, geolocalización y participación. Estudio de su presencia en las apps de la prensa española. Palabra Clave, 17 (3), 672-694. http://dx.doi.org/10.5294/pacla.2014.17.3.5

De Sola, J. (2020). La cobertura de la Cumbre del Clima Chile Madrid COP25 en los informativos de la radio española. AdComunica. Revista Científica del Estrategias, Tendencias e Innovación en Comunicación, 20, 205-230. http://dx.doi.org/10.6035/2174-0992.2020.20.9

Fidalgo, A. (2009). Pushed News: When the News Comes to the Cellphone. Brazilian Journalism Research, 5 (2), 113-124. https://doi.org/10.25200/BJR.v5n2.2009.214

García-Avilés, J. A., Carvajal, M. y Arias, F. (2018). Implantación de la innovación en los cibermedios españoles: análisis de las percepciones de los periodistas. Revista Latina de Comunicación Social, 73, 369-384. http://dx.doi.org/10.4185/RLCS-2018-1260

García, N. (2013). Presencia de las redes sociales y medios de comunicación: representación y participación periodística en el nuevo contexto social [Tesis, Universidad de Sevilla]. Repositorio institucional. https://idus.us.es/handle/11441/15976

Gil-Ramírez, M. y Gómez de Travesedo, R. (2016). Uso del smartphone en el periodismo actual: ¿hacia un nuevo modelo mediático? Estudio de caso del contexto malagueño. Ámbitos. Revista Internacional de Comunicación, 41, 5-21. https://doi.org/10.12795/Ambitos.2018.i41.01

Gómez-García, S., Gil-Torres, A., Carrillo-Vera, J., y Navarro-Sierra, N. (2019). Creando a Donald Trump: Las apps en el discurso político sobre el presidente de Estados Unidos. Comunicar, 59, 49-59. https://doi.org/10.3916/C59-2019-05 
Kemp, S. (2021). Digital 2021. Global overview report. https://wearesocial.com/digital-2021

Krippendorff, Klaus (2004). Content Analysis. And Introduction to its Methodology. Thousand Oaks.

Larrondo, A. y Teixeira, J. (2016). La convergencia narrativa en el periodismo móvil. Aproximación a la integración del contenido audiovisual en los productos nativos para iPad. Estudios sobre el Mensaje Periodístico, 22 (2), 777-792. http://dx.doi.org/10.5209/ESMP.54235

Ling, R., Fortunati, L., Goggin, G., Lim, S. S. y Li, Y. (eds.) (2020). The Oxford Handbook of Mobile Communication and Society. Oxford University Press.

López-García, X., Silva-Rodríguez, A., Vizoso-García, A. A., Westlund, O. y Canavilhas, J. (2019). Periodismo móvil: Revisión sistemática de la producción científica. Comunicar, 59 (27), 9-18. https://doi.org/10.3916/C59-2019-01

Manovich, L. (2013). El software toma el mando. UOC.

Márquez, I. (2017). El Smartphone como metamedio. Observatorio. Investigaçáo e Saber em Comunicaçáo, 11 (2). https://doi.org/10.15847/obsOBS11220171033

Martínez, F. (2014). Los nuevos medios y el periodismo de medios sociales [Tesis, Universidad Complutense de Madrid]. Repositorio institucional. https://eprints.ucm.es/id/eprint/24592/

Mena, M. (2020). Android e iOS dominan el mercado de los smartphones. Statista. https://es.statista.com/grafico/18920/cuota-de-mercado-mundial-de-smartphones-por-sistemaoperativo/\#: :text=Seg\%C3\%BAn\%20datos\%20de\%201a\%20consultora,Apple\%20casi\%20e1\%2 $\underline{014 \% 25 \% 20 \text { restante }}$

Nel, F. y Westlund, O. (2012). The 4cs' of Mobile News: Channels, conversation, content and commerce. Journalism Practice, 6 (5-6), 744-753. https://doi.org/10.1080/17512786.2012.667278

Newman, N., Fletcher, R., Kalogeropoulos, A. y Nielsen, R. K. (2019). Reuters Institute Digital News Report 2019. Reuters Institute for the Study of Journalism. https://reutersinstitute.politics.ox.ac.uk/sites/default/files/inline-files/DNR_2019_FINAL.pdf

Olivero, E. (2018). El Uso de las Apps en España y en el Mundo en 2018. https://pickaso.com/2018/uso-apps-espana-y-mundo-2018

Parra, D. (2008). Ciberperiodismo móvil: el peso específico de la cuarta pantalla en el panorama informativo internacional. Re-presentaciones: periodismo, comunicación y sociedad, 2(4), 73-91. Disponible en https://dialnet.unirioja.es/servlet/articulo?codigo $=2990230$

Peinado, F. y Mateos, J. P. (2016): Promoción y monetización de las aplicaciones móviles editoriales, Icono 14, 14 (2): 329-352. https://doi.org/10.7195/ri14.v14i2.974

Pulgar, F. y Maniega, D. (2012). Liburutegiak: una aplicación para servicios bibliotecarios en Red. VI Congreso Nacional de Bibliotecas Públicas. Jaén, España. http://travesia.mcu.es/portalnb/jspui/bitstream/10421/6745/1/liburutegiak.pdf 
RLCS, Revista Latina de Comunicación Social, 79, 283-302

[Investigación] DOI: 10.4185/RLCS-2021-1516| ISSN 1138-5820| Año 2021

Ramos del Cano, F. y González-Molina, S. (2015). Una propuesta de análisis metodológico para evaluar las app informativas de los medios de comunicación. En Sabés, F. y Verón, J. J. (coords.). Innovación y cambio en la comunicación postindustrial. Asociación de Periodistas de Aragón.

Read, M. (2017). Analysis: The Reality of Online News Consumption. Mediatel. https://mediatel.co.uk/news/2017/07/31/analysis-the-reality-of-online-news-consumption

Rivero, F. (2018). Mobile en España y en el mundo 2018. https://mktefa.ditrendia.es/hubfs/DitrendiaInforme\%20Mobile\%202018.pdf?utm campaign=Informe\%20Mobile\%202018\&utm medium=e mail\&_hsmi $=64334773 \&$ hsenc $=$ p2ANqtz-

8eqABfU3baOqFeey94FwzS_A6IP4BMZK2fwww6LojlkzyC7LAeJJ0JugwgFJhoQGqjXrbLwPd xVPtxUY74fS7dh1kiuw\&utm_content=64334773\&utm_source=hs_automation

Robledo-Dioses, K. (2017). Evolución del periodismo: aportes mediáticos a la consolidación de la profesión. Comhumanitas: revista científica de comunicación, 8(1), 1-27. https://dialnet.unirioja.es/descarga/articulo/6057561.pdf

Rom, S. y Reich, Z. (2017). Between the technological hare and the journalistic tortoise: Minimization of knowledge claims in online news flashes. Journalism, 21, 54-72. https://doi.org/10.1177/1464884917740050

Sánchez-Aranda, J. J. (2005). Análisis de contenido cuantitativo de medios. En Berganza, M. R. y Ruiz, J. A. (coords). Investigar en Comunicación. Guía práctica de métodos y técnicas de investigación social en Comunicación. McGraw Hill.

Valverde, E. y Aguado, J. (2010). Dispositivos móviles y convergencia digital en los grupos de comunicación españoles: la perspectiva de los profesionales. II Congreso Internacional AE-IC: Comunicación y desarrollo en la era digital. Málaga, España. http://www.aeic.org/malaga2010/upload/ok/95.pdf

Varona-Aramburu, D.; Sánchez-Martín, M.; Arrocha, R. (2017). Consumo de información política en dispositivos móviles en España: caracterización del usuario tipo y su interacción con las noticias. El profesional de la información, 26 (4), 641-648. https://doi.org/10.3145/epi.2017.jul.08

Victoria, J. (2002). El análisis de contenido: una técnica para explorar y sistematizar información. $\begin{array}{lllll}\text { XXI. Revista de Educación, } & \text { 95-105. }\end{array}$ http://rabida.uhu.es/dspace/bitstream/handle/10272/1913/b15141895.pdf?sequence=1

Westlund, O. (2015). News Consumption in an Age of Mobile Media: Patterns, People, Place and Participation. Mobile Media \& $\quad$ Communication, $3 \quad$ (2). http://dx.doi.org/10.1177/2050157914563369

Wheatley, D. y Ferrer-Conill, R. (2020). The Temporal Nature of Mobile Push Notification Alerts: A Study of European News Outlets' Dissemination Patterns. Digital Journalism. https://doi.org/10.1080/21670811.2020.1799425

Wimmer, Roger y Dominick, Joseph (1996). La investigación científica de los medios de comunicación. Una introducción a sus métodos. Bosch Comunicación 


\section{AUTOR/ES:}

\section{Javier de Sola Pueyo}

Doctor en Comunicación, Master en Marketing y Comunicación Corporativa y Licenciado en Periodismo. Profesor de la Universidad de Zaragoza desde el curso 2016/2017 y director del programa Despierta Aragón de Aragón Radio, la radio autonómica aragonesa. Miembro del Grupo de Investigación en Comunicación e Información Digital (GICID). En la actualidad centra sus investigaciones en las características y evolución del medio radiofónico y en el tratamiento de diferentes asuntos de actualidad en los medios de comunicación.

Correo electrónico: jdesola@unizar.es

Índice $\mathrm{H}: 1$

Orcid ID: https://orcid.org/0000-0003-3006-8236

Google Scholar: https://scholar.google.es/citations?user=Mp54gtIAAAAJ\&hl=es\&oi=sra

\section{Miguel Ángel Ortiz Sobrino}

Profesor Titular de la Universidad Complutense de Madrid. Director del Master de Realización y Diseño de programas y formatos en televisión. Investigador en el proyecto "Youtubers e instagrammers: la competencia mediática en los prosumidores emergentes" MEC. RTI2018-093303B-I00.

Correo electrónico: maortiz@ ccinf.ucm.es

Índice Hi: 40

Orcid ID: https://orcid.org/0000-0003-0103-9524

Google Scholar: https://scholar.google.es/citations?user=3OCGQs4AAAAJ\&hl=es 